Medical Care to Children in a War Region

Prof. Victor N. Preobrazhensky, ${ }^{1}$ Prof. Vladimir Rozinov,

$M D{ }^{2}$ Vladimir Petlakb, $M D^{1}$

1. Russian Center of Disaster Medicine \& Protection, Moscow, Russia

2. Moscow Scientific Research Institute for Child Surgery, Russia

Introduction: Field hospitals of the Russian Center of Disaster Medicine were formed on the basis of children's surgeons and anesthesiologists. Later, a brigade of pediatrics was formed, and, at last, a children's field hospital (CFH) was founded, and began to work in the Chechen Republic. Methods: The structure of $\mathrm{CFH}$ included: (1) A diagnostic block containing $x$-ray equipment, ultrasound scanner, endoscopes, and a clinical laboratory; (2) an operational block; (3) wards for 50 patients; (4) a reanimation department; and (5) a consulting department. The medicines, as well as electricity and oxygen, were provided independently. Communication was carried out using a satellite antenna. The children's doctors included surgeons, pediatricians, neuropathologists, anesthesiologists, and endoscopic support. Among the children's surgeons were experts in orthopedics, combustology, urology, thoracic surgery, and neurosurgery. Results: Within a year of work (April 2001-April 2002), doctors at the hospital consulted 32,300 outpatients, treated 2,645 inpatients, and performed 2,054 surgical operations. Special organization of the surgery was necessary in the cases of mass delivery of the injured. For example, when 36 wounded were delivered at the same time to the hospital after a bomb explosion. A total of 339 patients were treated in reanimation; 44 died. Sixty-four telemedicine consultations for the most difficult patients were arranged with the help of the best Russian clinics of Moscow and the North Caucasus region. Seventy-three patients were transported to specialized hospitals.

Conclusion: Modern equipment for diagnosis and treatment, the high qualification of the medical staff in the $\mathrm{CFH}$, and telemedicine consultation made it possible to provide specialized medical care in the war region.

Keywords: bomb; Chechen Republic; children; explosion; field hospital; reanimation; referrals; Russian; surgery; telemedicine; war Prehosp Disast Med 2003:18:s(1)s19.

E-mail: hospital@petlakh.msk.ru

\section{The System of Anti-Epidemic Measures Against Biological Acts of Terrorism}

N.I. Batrac, MD; A.A. Shaposhnikov

All-Russian Centre for Disaster Medicine ("Zaschita"), Moscow, Russia

Nowadays, we are anxious about the danger of biological terrorism. Thus, the arrangement and undertaking of counteraction measures to protect the population effectively against bioterrorism is of great importance. Research by the Disaster Medicine Services, the working conditions in biological emergencies, and the experience of defeating various epidemics demonstrate that in each country and in each emergency, the health services will face the following concrete tasks:

1. Timely recognition of the fact that biological components were used;
2. Finding out what kind of component was used, the size of the infected territory, and the number of victims;

3. Isolation of the epidemic center;

4. Implementation of urgent anti-epidemic, medical, and evacuation measures at the epidemic site;

5. Implementation of the whole range of sanitary-epidemiological, medical, and evacuation measures to completely eliminate the consequences of the use of biological components.

The main role in eliminating the consequences of biological acts of terrorism requires the engagement of the specialized detachments of the State Sanitary and Epidemiological Service, which is the part of the Disaster Medicine Service of the Russian Ministry of Health. Disaster medicine centers and other medical institutions are responsible for providing medical help and evacuation of people. Infected patients are treated in local medical institutions, which are closest to the epidemic site. Special committees for counteracting the acts of biological terrorism generally manage the liquidation of the consequences of epidemic emergencies.

Keywords: detection; disaster medicine; epidemics; evacuation; isolation; liquidation; responses; terrorism, biological; treatment Prebosp Disast Med 2003:18:s(1)s19.

E-mail: rcdm.org@ru.net

\section{The United States Experience with Smallpox Vaccine: 2003 \\ Col. Tom Stein, $M D$ \\ MEDCOM, Health Care Operations, Office of the Surgeon General}

The civilian and military experience with the smallpox vaccine will be presented, including complications, outcomes, and lessons learned.

Keywords: complications; experience; lessons learned; military; outcome; smallpox; vaccine

Prehosp Disast Med 2003:18:s(1)s19.

E-mail: tstein@wpahs.org

\section{Free Topics}

\section{Epidemiological Characteristics and Military Implications of Hemorrhagic Fever with Renal Syndrome in Croatia} Rosanda Mulic, MD, PhD; Darko Ropac, MD, $P b D$ Naval Medical Institute of the Croatian Army, Croatia

The aim of this study was to describe epidemiological characteristics of hemorrhagic fever with renal syndrome in Croatia, and to identify their military implications. The data from obligatory infectious diseases reports and notification of deaths due to infectious diseases were analyzed, along with the data on the epidemics of hemorrhagic fever with renal syndrome in Croatia, and then they were compared with data from this study.

During the period between 1987 and 2002, 555 cases of hemorrhagic fever with renal syndrome were recorded in Croatia, 160 (28.8\%) of these among soldiers. The mortality rate was as high as $15.4 \%$ (mean $=1.1 \% ; 6 / 555)$. The highest number of cases (317) were recorded during 2002. 